\title{
VIOLAÇÕES DOS DIREITOS HUMANOS NO SISTEMA PRISIONAL BRASILEIRO: O CASO DO COMPLEXO PENITENCIÁRIO DE PEDRINHAS EM SÃO LUÍS- MARANHÃO
}

\author{
José Eliomar Quirino Júnior ${ }^{1}$
}

\begin{abstract}
RESUMO: O artigo tem como propósito analisar e compreender a realidade do sistema penitenciário no Brasil a partir do caso do Complexo Penitenciário de Pedrinhas e das violações de Direitos Humanos no período entre 2013 - 2015. Para isso, objetiva-se construir argumentos para a seguinte problemática: "as violações de direitos humanos no caso de Pedrinhas ferem os compromissos assumidos pelo Brasil?” Assim, a pesquisa irá reunir dados e informações a serem relacionados com os estudos teóricos com o intuito de compreender o assunto e de que forma as violações têm ocorrido. Portanto, conclui-se que as garantias legais às quais o Brasil se submete vêm sendo descumpridas no que se refere à garantia dos direitos das pessoas sob medidas restritivas de liberdade.
\end{abstract}

Palavras-chave: Direitos humanos. Relações internacionais. Sistema prisional. Tortura. Pedrinhas.

ABSTRACT: The article aims to analyze and understand the reality of the penitentiary system in Brazil from the case of the Pedrinhas Penitentiary Complex and the human rights violations in the period between 2013 - 2015. For this purpose, the objective is to build arguments for the following problem: "Do human rights violations in the case of Pedrinhas affect the commitments made by Brazil?” Thus, the research will gather data and information to be related to theoretical studies in order to understand the subject and how the violations have occurred. Therefore, it is concluded that the legal guarantees to which Brazil is subject have been breached with regard to guaranteeing the rights of people under restrictive measures of freedom.

Keywords: Human rights. International relations. Prison system. Torture. Pedrinhas.

\section{INTRODUÇÃO}

De acordo com a Organização das Nações Unidas (ONU) ${ }^{2}$, os Direitos Humanos podem ser entendidos como sendo uma garantia fundamental e universal que têm como

\footnotetext{
${ }^{\mathrm{I}}$ Bacharel em Relações Internacionais pelo Instituto de Educação Superior de Brasília - IESB - Centro Universitário, Brasília - DF, concluído em 2021.I. Graduando em Línguas Estrangeiras Aplicadas ao Multilinguismo e à Sociedade da Informação - LEA/MSI, $3^{\circ}$ semestre, na Universidade de Brasília - UnB. Atua como estagiário na Coordenação de Política de Classificação Indicativa - Ministério da Justiça e Segurança Pública - MJSP, Brasília - DF. Trabalhou como estagiário na Assessoria Internacional do Ministério do Turismo - Mtur, Brasília - DF.Trabalhou como estagiário na Representação Brasileira no Parlamento do Mercosul - Câmara dos Deputados, Brasília - DF. E-mail: eliomar.jr23@gmail.com.
} 
fim proteger os indivíduos e os grupos sociais contra ações e omissões que possam ameaçar a dignidade da pessoa humana. Em ıo de dezembro de 1948, a Organização das Nações Unidas promulgou a Declaração Universal dos Direitos Humanos (DUDH) ${ }^{3}$. Essa foi uma medida em razão das violências cometidas nas duas guerras mundiais, mas também representou o estabelecimento de uma busca de muitos anos almejando garantir condições mínimas para qualquer ser humano.

No que se refere ao vínculo entre Direitos Humanos e Relações Internacionais, nota-se uma íntima relação entre ambos ao passarem por processos históricos e de aperfeiçoamento ${ }^{4}$. Para exemplificar, a mera Declaração Universal dos Direitos Humanos, não vinculante, necessita de uma articulação internacional para que as recomendações produzam efeitos no ordenamento interno dos Estados. Nesse sentido, fica evidente a interseção e a relevância para o panorama internacional quanto aos dois campos de estudo.

A pesquisa tem como objetivo analisar e compreender a realidade do sistema penitenciário no Brasil a partir do caso do Complexo Penitenciário de Pedrinhas e das violações de Direitos Humanos no período entre 2013 - 2015. Diante disso, a pergunta de pesquisa é "as violações de direitos humanos no caso de Pedrinhas ferem os compromissos assumidos pelo Brasil?” Considerando as denúncias apresentadas à ONU, o informe oficial do relator da ONU e a crise carcerária nacional pode-se afirmar que o Estado brasileiro fere as garantias constitucionais e normas internacionais (o Pacto de São José da Costa Rica, o Pacto Internacional sobre Direitos Civis e Políticos, entre outras) em matéria de direitos humanos.

É válido ressaltar que, segundo o Departamento Penitenciário Nacional (Depen), órgão vinculado ao Ministério da Justiça e Segurança Pública - MJSP, o Brasil é o terceiro país com mais pessoas presas, ficando atrás apenas dos Estados Unidos e China.

Sobre o Complexo Penitenciário de Pedrinhas, São Luís, Maranhão, a unidade possui um histórico de violações de Direitos Humanos que revela uma situação caótica nas

\footnotetext{
${ }^{2}$ ONU - ORGANIZAÇÃO DAS NAÇÕES UNIDAS. Declaração Universal dos Direitos Humanos da ONU. Disponível em https://brasil.un.org/pt-br/916or-declaracao-universal-dos-direitos-humanos. Acesso em: I8 mar. 2021.

3 BRASIL. Decreto $\mathrm{n}^{\circ}$ 19.841, de 22 de outubro de 1945. Declaração Universal dos Direitos Humanos (DUDH). Disponível em http://www.planalto.gov.br/ccivil_03/decreto/1930-1949/Di984I.htm. Acesso em: I8 mar. 202I.

${ }^{4}$ SALA, José Blanes. Relações internacionais e Direitos humanos. Revista Cultura Acadêmica; Marília: Oficina Universitária. Io6p. São Paulo, 20II.
} 
suas carceragens. Em razão disso, o Brasil vem sendo monitorado e questionado por órgãos internacionais, como a ONU e a Organização dos Estados Americanos (OEA) ${ }^{5}$, pelas situações que ameaçam à vida e à integridade física e moral dos apenados.

Analisando esse contexto, o presente artigo baseia-se na noção de que caso a política de aprisionamento continue a seguir a tendência de crescimento, apesar da queda no primeiro semestre de 2020, em relação a 2019 , de 359,40\% para 323,04\%, segundo o Sistema de Informações do Departamento Penitenciário - SISDEPEN ${ }^{6}$, a superlotação dos presídios irá se tornar insustentável. Assim como, essa política acaba implicando diretamente no agravamento das violações de Direitos Humanos, a exemplo das questões sanitárias nas unidades.

No que se refere aos compromissos assumidos pelo Brasil em matéria de Direitos Humanos, têm-se um rol de regulamentos. No nível internacional, o Brasil é parte dos principais tratados de direitos humanos das Nações Unidas que proíbem a tortura e os maus-tratos, incluindo o Pacto Internacional sobre Direitos Civis e Políticos (1966) ${ }^{7}$ e os dois Protocolos Opcionais; a Convenção contra a Tortura e Outras Pessoas Cruéis, Desumanas ou Punição ou Tratamento Degradante ${ }^{8}$ e o Protocolo Opcional ao mesmo; e a

Convenção Internacional para a Proteção de Todas as Pessoas contra o Desaparecimento Forçado?.

Assim como, a Convenção sobre os Direitos da Criança ${ }^{\mathrm{IO}}$; a Convenção Internacional sobre a Eliminação de todas as Formas de Raça Discriminação ; a

${ }^{5}$ OEA - ORGANIZAÇÃO DOS ESTADOS AMERICANOS. Disponível em http://www.oas.org/pt/. Acesso em: I8 mar. 202I.

${ }^{6}$ DePen - Departamento PEnitenciário NACIONAl. Depen lança dados do Sisdepen do primeiro semestre de 2020. Disponível em https://www.gov.br/depen/pt-br/assuntos/noticias/depen-lancadados-do-sisdepen-do-primeiro-semestre-de2020\#: : :text=O\%20n\%C $3 \%$ BAmero\%2ototal\%2ode\%2opresos,d\% $\mathrm{C}_{3 \%}$ A9ficit\%2ode\%2ovagas\%2otamb\% $\mathrm{C}_{3 \%}$ A9m\%2ocaiu. Acesso em: 30 mar. 2021.

7 OAS - ORGANIZATION OF AMERICAN STATES. Pacto Internacional sobre Direitos Civis e Políticos (1966). Disponível em https://www.oas.org/dil/port/1966\%20Pacto\%2oInternacional\%20sobre\%20Direitos\%20Civis\%20e\%20Pol\% C3\%ADticos.pdf. Acesso em: os mai. 2021.

${ }^{8}$ BRASIL. Decreto no 40 , de Is de fevereiro de 1991. Convenção Contra a Tortura e Outros Tratamentos ou Penas Cruéis, Desumanos ou Degradantes. Diário Oficial da União: p. 3012, col. 2, Brasília, DF, i8 fev. I99I.

${ }^{9}$ PLANALTO. Decreto ${ }^{\circ} 8767$, de II de maio de 2016. Convenção Internacional para a Proteção de Todas as Pessoas contra o Desaparecimento Forçado. Disponível em http://www.planalto.gov.br/ccivil_03/_atozor52018/2016/decreto/D8767.htm. Acesso em o5 mai. 2021.

${ }^{10}$ PLANALTO. Decreto $n^{\circ}$ 99710, de Ir de novembro de 1990. Convenção sobre os Direitos da Criança. Disponível em http://www.planalto.gov.br/ccivil_03/decreto/1990-1994/d99710.htm. Acesso em o5 mai. 2021. 
Convenção sobre a Eliminação de Todas as Formas de Discriminação contra Mulheres ${ }^{\mathrm{I2}}$; a Convenção sobre os Direitos das Pessoas com Deficiência ${ }^{\mathrm{I}}$ e seu Protocolo Facultativo; a Convenção Internacional sobre a Proteção dos Direitos de todos os Trabalhadores Migrantes e Membros de suas Famílias ${ }^{\mathrm{I}}$; a Convenção relativa ao Estatuto dos Refugiados ${ }^{15}$; e a Convenção relativa ao Status de Pessoas Apátridas ${ }^{16}$. O Brasil também é signatário do Estatuto de Roma do Crime Internacional Quadra ${ }^{\mathrm{I}}$.

Enquanto que no âmbito regional, o Brasil é parte dos principais tratados de direitos humanos da Organização dos Estados Americanos, incluindo a Convenção Americana sobre Direitos Humanos (1969) ${ }^{18}$; a Convenção Interamericana para Prevenir e Punir a Tortura ${ }^{19}$; a Convenção Interamericana sobre Desaparecimento Forçado de Pessoas $^{20}$; a Convenção Interamericana para a Prevenção, Punição e Erradicação da

${ }^{11}$ PLANALTO. Decreto ${ }^{\circ}$ 65810, de o8 de dezembro de 1969. Convenção Internacional sobre a Eliminação todas as Formas de Raça Discriminação. Disponível em http://www.planalto.gov.br/ccivil_03/decreto/1950-1969/D65810.html. Acesso em 05 mai. 2021.

${ }^{12}$ PLANALTO. Decreto $n^{\circ} 4377$, de 13 de setembro de 2002. Convenção sobre a Eliminação de Todas as

Formas de Discriminação contra $\quad$ Mulheres. $\quad$ Disponível $\mathrm{em}$
http://www.planalto.gov.br/ccivil_03/decreto/2002/d4377.htm. Acesso em o5 mai. 202I.

${ }^{13}$ PLANALTO. Decreto $n^{\circ}$ 6949, de 25 de agosto de 2009. Convenção sobre os Direitos das Pessoas com Deficiência. Disponível em http://www.planalto.gov.br/ccivil_03/_ato2007-2010/2009/decreto/d6949.htm. Acesso em o5 mai. 202I.

${ }^{14}$ OAS - ORGANIZATION OF AMERICAN STATES. Convenção Internacional sobre a Proteção dos Direitos de todos os Trabalhadores Migrantes e Membros de suas Famílias. Disponível em https://www.oas.org/dil/port/1990\%20Conven\% $\mathrm{C}_{3} \% \mathrm{~A}$ 7\% $\mathrm{C}_{3 \%}$ A30\%2oInternacional\%20sobre\%20a\%20 Prot

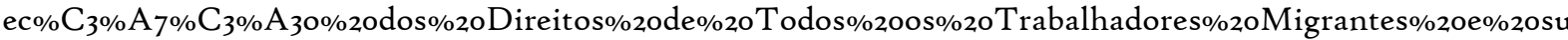

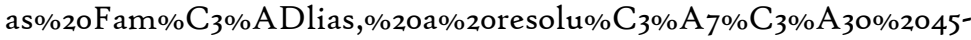

158\%2ode\%2018\%2ode\%2odezembro\%2ode\%201990.pdf. Acesso em: os mai. 2021.

${ }^{15}$ CÂMARA DOS DEPUTADOS. Decreto n ${ }^{\circ} 50215$, de 28 de janeiro de 1961. Convenção relativa ao Estatuto dos Refugiados. Disponível em https://www2.camara.leg.br/legin/fed/decret/196o-1969/decreto-50215-28janeiro-1961-389887-publicacaooriginal-I-pe.html. Acesso em o5 mai. 2021.

${ }^{16}$ PLANALTO. Decreto $\mathrm{n}^{\circ}$ 4246, de 22 de maio de 2002. Convenção relativa ao Status de Pessoas Apátridas. Disponível em http://www.planalto.gov.br/ccivil_03/decreto/2002/D4246.htm. Acesso em 05 mai. 2021.

${ }^{17}$ PLANALTO. Decreto $\mathrm{n}^{\circ} 4388$, de 25 de setembro de 2002. Estatuto de Roma do Crime Internacional Quadra. Disponível em http://www.planalto.gov.br/ccivil_03/decreto/2002/d4388.htm. Acesso em o5 mai. 202I.

${ }^{18} \mathrm{CIDH}$ - COMISSÃO INTERAMERICANA DE DIREITOS HUMANOS. Convenção Americana sobre Direitos Humanos. $\quad$ Disponível em https://www.cidh.oas.org/basicos/portugues/c.convencao_americana.htm. Acesso em: 05 mai. 202I.

${ }_{19}$ PLANALTO. Decreto $\mathrm{n}^{\circ}$ 98386, de 09 de dezembro de 1989. Convenção Interamericana para Prevenir e Punir a Tortura. Disponível em http://www.planalto.gov.br/ccivil_03/Decreto/I98o-I989/D98386.htm. Acesso em o5 mai. 2021.

${ }^{20}$ PLANALTO. Decreto $n^{\circ} 8766$, de in de maio de 2016. Convenção Interamericana sobre Desaparecimento Forçado de Pessoas. Disponível em http://www.planalto.gov.br/ccivil_03/_ato20152018/2016/decreto/D8766.htm. Acesso em o5 mai. 2021. 
Violência contra a Mulher ${ }^{21}$; e a Convenção Interamericana Contra o Racismo, Discriminação Racial e Formas Relacionadas de Intolerância ${ }^{22}$. O estado também reconhece a jurisdição da Corte Interamericana de Direitos Humanos.

No que se refere à Constituição Federal, é o principal instrumento político e jurídico do Brasil que declara garantias. Já para cada um dos 26 estados também possuem constituição própria, estabelecida pelo artigo 25 da Constituição Federal, e o Distrito Federal possui Lei Orgânica própria, conforme artigo 32 da Constituição.

Dessa forma, a pesquisa irá reunir dados e informações a serem relacionados com os estudos teóricos com o intuito de compreender sobre quais bases a temática está assentada e de que forma as violações têm ocorrido. Para isso, o artigo será composto por uma introdução; uma seção sobre Direitos Humanos e ONU; outra sobre a situação do sistema prisional no Brasil; uma parte reservada às violações de Direitos Humanos no Complexo Penitenciário de Pedrinhas e as observações finais.

\section{Direitos humanos e ONU}

Segundo a organização internacional Unidos para os Direitos Humanos ${ }^{23}$, a evolução dos direitos humanos teve seu início na Babilônia até alcançar a Índia, a Grécia e chegando à Roma. Foi nesse período que surgiu o conceito de "lei natural" ou "direito natural”, na observação de que o homem tendia a seguir leis não escritas, já o direito romano baseava-se em ideias racionais originadas da essência natural das coisas.

Alguns documentos do período são considerados como um marco para o surgimento e o reconhecimento dos direitos individuais, são eles: a Carta Magna (I215), a Petição de Direito (1628), a Constituição dos Estados Unidos (1787), a Declaração Francesa dos Direitos do Homem e do Cidadão (1789), a Declaração dos Direitos dos Estados

\footnotetext{
${ }^{21}$ PLANALTO. Decreto $\mathrm{n}^{\circ}$ 1973, de $\mathrm{I}^{\circ}$ de agosto de 1996. Convenção Interamericana para a Prevenção, Punição e Erradicação da Violência contra a Mulher. Disponível em http://www.planalto.gov.br/ccivil_03/decreto/r996/di973.htm. Acesso em 05 mai. 2021.

${ }^{22}$ CUT - CENTRAL ÚNICA DOS TRABALHADORES. Convenção Interamericana Contra o Racismo, Discriminação Racial e Formas Relacionadas de Intolerância. Disponível em https://www.cut.org.br/system/uploads/ck/files/interamericantreatiesA68ConvencaoInteramericanaracismoPOR.pdf. Acesso em: os mai. 2021.

${ }^{23}$ UNIDOS PARA OS DIREITOS HUMANOS. Uma breve História dos Direitos Humanos. Disponível em https://www.unidosparaosdireitoshumanos.com.pt/what-are-human-rights/brief-history/. Acesso em: 04 mai. 2021.
} 
Unidos (179I) e outros. Estes são alguns dos principais escritos que antecedem muitos dos documentos de direitos humanos contemporâneos ${ }^{24}$.

No processo de evolução dos direitos humanos, surgiu a teoria das gerações ou dimensões dos direitos humanos que foi lançada pelo jurista francês Karel Kasak. Em ocasião da Conferência proferida no Instituto Internacional de Direitos Humanos de Estrasburgo (França), no ano de 1979, Kasak classificou os direitos humanos em três gerações, cada qual com aspectos próprios. Posteriormente, alguns autores passaram a defender a ampliação dessa classificação para quatro ou até cinco gerações.

"As classificações foram embasadas no período nomeado de Revolução Francesa (1789-1799) e ligadas ao lema do movimento: "liberté, egalité et fraternité" (liberdade, igualdade e fraternidade). Assim, a primeira geração refere-se à 'liberdade'; a segunda geração ligada à 'igualdade'; e por fim, a terceira geração fazendo referência à 'fraternidade'" 25 .

"Em um primeiro momento, a primeira geração compreende os direitos de liberdade que englobam os direitos civis e políticos" ${ }^{26}$. Estes são os direitos às prestações negativas do Estado, ou seja, este deve se abster do poder. Mas também se faz necessário a prestação ativa garantindo, por exemplo, a segurança administrativa e a justiça. Esses direitos também são conhecidos como "direitos de defesa" protegendo o indivíduo contra as intervenções autoritárias do Estado. As revoluções liberais do século XVIII na Europa e nos Estados Unidos são alguns dos marcos históricos.

A segunda geração de Vasak (1979) refere-se ao direito de igualdade (saúde, educação, previdência social, habitação e outros), portanto, exige do Estado um papel ativo, em especial, o de fiscalização. Por conseguinte, têm-se como marcos históricos a Constituição Mexicana de 1917, que regulou o direito ao trabalho e à previdência social; a Constituição Alemã de Weimar de 1919; e no Direito Internacional, o Tratado de Versalhes que criou a Organização Internacional do Trabalho.

Enquanto, a terceira geração de Vasak (1979) caracteriza os direitos de titularidade da comunidade em seu sentido amplo e não mais de caráter individual. Dentre eles,

\footnotetext{
${ }^{24}$ UNIDOS PELOS DIREITOS HUMANOS. As origens dos Direitos Humanos. Disponível em https://www.unidosparaosdireitoshumanos.com.pt/course/lesson/background-of-human-rights/thebackground-of-human-rights.html. Acesso em: 04 mai. 2021.

${ }^{25}$ RAMOS, André de Carvalho. Curso de direitos humanos. - 4. ed. - São Paulo: Saraiva, 2017.

${ }^{26}$ RAMOS, André de Carvalho. Curso de direitos humanos. - 4. ed. - São Paulo: Saraiva, 2017.
} 
destaca-se o direito ao desenvolvimento, à paz, à autodeterminação e ao meio ambiente equilibrado. Também são conhecidos como direitos de solidariedade visando a disposição dos recursos do planeta para todos.

No século XX, autores como Paulo Bonavides defendem a quarta geração de direitos que resultaria da globalização dos direitos humanos como a participação democrática, o pluralismo, a bioética e a questão da manipulação genética. Bonavides (2006) elenca ainda a quinta geração que seria o direito à paz em toda a humanidade (direito de terceira geração de Vasak). Nesse sentido, percebe-se que há uma contradição na visão dos autores quanto à classificação. Como também, há críticas quanto à validade da ampliação das gerações.

Após a Segunda Guerra Mundial, disseminou-se a consciência de que não se poderia permitir a repetição da violência causada pelas guerras. Fundada em 1945, as Nações Unidas buscavam prevenir atrocidades futuras por meio da afirmação, em sua carta de fundação, do reconhecimento dos direitos humanos fundamentais. A dignidade e a importância do ser humano e o compromisso de promover melhor qualidade de vida e mais liberdade. Nos anos seguintes, Estados-membros das Nações Unidas buscaram desenvolver as determinações sobre direitos humanos estabelecidas pela Carta e reuni-las em um único documento.

O trabalho de elaboração do documento durou cerca de três anos, quando no dia Io de dezembro de 1948, a Assembleia Geral da ONU adotou a Declaração Universal dos Direitos Humanos como uma norma comum para ser atingida por todos os povos e todas as nações. No discurso de H.V. Evatt, Presidente da Assembleia Geral das Nações Unidas em 1948, ele declarou:

A adoção da Declaração é o primeiro passo em um grande processo de evolução. É a primeira ocasião em que a comunidade organizada de nações realizou uma declaração sobre direitos humanos e liberdades fundamentais. E ela conta com a autoridade da corrente de opiniões das Nações Unidas como um todo. Milhões de pessoas, homens, mulheres e crianças em todo o mundo vão ajudar a guiar e a inspirar esse documento. (EVATT, 1948).

Diante disso, percebe-se que a declaração implica em uma correspondência junto aos instrumentos de direitos humanos, as constituições $e$ as leis que constituem os ordenamentos que asseguram os direitos humanos. Além disso, a Declaração resultou na criação de organizações e mecanismos internacionais de defesa dos direitos humanos. Os 
princípios da Declaração ressaltaram as dificuldades da descolonização e foram agregadas nas constituições dos países recém-estabelecidos que se juntaram às Nações Unidas.

A declaração inspirou ainda os sistemas nacionais e regionais de proteção dos direitos humanos, incluindo leis e instituições. E continua a guiar o trabalho dos defensores dos direitos humanos e de seus aliados pelo mundo. Hoje a Declaração da ONU está disponível em mais de 500 idiomas e dialetos, além de ser um dos documentos mais traduzidos. O dia ıo de dezembro, dia em que a declaração foi adotada, é celebrado anualmente como o Dia dos Direitos Humanos e enfatiza a relevância dos direitos humanos no dia a dia.

Isso, a fim de que haja efetividade dos direitos declarados e a possibilidade de serem reivindicados. Isso pode ser confirmado no artigo oitavo da referida declaração que enuncia o seguinte trecho: "Toda a pessoa tem direito a recurso efetivo para as jurisdições nacionais competentes contra os atos que violem os direitos fundamentais reconhecidos pela Constituição ou pela lei” ${ }^{27}$. Logo, todos as pessoas têm o direito de dignidade e liberdade em todos os espaços sem que sofram discriminação.

Como mais um mecanismo para garantir os direitos humanos a todas as pessoas, o

Conselho de Direitos Humanos da ONU - CDH foi criado em 9 de maio de 2006 e tem a sua sede em Genebra, na Suíça. Baseado na Carta da ONU de 1945, o órgão é formado por 47 Estados-membros, entre eles o Brasil com status de membro consultivo. Nesse sentido, o Conselho de Direitos Humanos assumiu o mesmo papel e responsabilidades do Alto Comissariado das Nações Unidas para os Direitos Humanos - ACNUDH; porém, mantendo independência nos seus papéis e cooperando para a promoção e proteção de todas as garantias reconhecidas.

Dessa forma, uma das responsabilidades desse órgão é realizar a Revisão Periódica Universal - RPU que tem como objetivo avaliar o respeito aos direitos humanos dos 193 Estados membros da ONU. Para isso, o Conselho conta com o trabalho de peritos independentes e relatores especiais que vão até os países em missão para colher informações e documentar possíveis divergências entre as práticas dos Estados e os compromissos assumidos.

${ }^{27}$ JUS BRASIL. Supremo Tribunal Federal. Íntegra da Declaração Universal dos Direitos Humanos. Disponível em https://stf.jusbrasil.com.br/noticias/362108/integra-da-declaracao-universal-dos-direitoshumanos. Acesso em: 04 mai. 202I. 
Entre as temáticas mais recentes tratadas no âmbito do Conselho de Direitos Humanos da ONU estão o trabalho escravo, violações do sistema prisional, abuso da força policial no Brasil e políticas anti-migratórias. No que se refere a temática dos tratamentos cruéis ou degradantes, tem-se o Departamento sobre Tortura que integra o referido Conselho.

Portanto, nota-se que o aumento da população prisional no Brasil vem trazendo desafios no campo da garantia de direitos. Assim, discussões como a pena não apenas como mera punição tem ganhado pauta, pois percebe-se a necessidade de que pessoas em conflito com a lei passem por um processo de recuperação. Para isso, o modelo repressivo, unicamente, precisa ser deixado de lado para dar espaço à reintegração social do preso, objetivo da Lei de Execução Penal (Lei n ${ }^{\circ}$ 7.210, de II de julho de 1994) ${ }^{28}$. Esta que busca prevenir novos crimes e preparar a pessoa presa para voltar à vida social sem distinção.

\section{Situação do sistema prisional no Brasil}

De modo geral, os Direitos Humanos buscam garantir o tratamento digno de todas as pessoas em um âmbito universal. Dentre alguns dos grupos que estão mais propensos a sofrerem violações ou restrições de direitos estão aqueles que integram o sistema prisional. Por isso, no I $^{\circ}$ Congresso das Nações Unidas sobre Prevenção do Crime e Tratamento de Delinquentes, em 1955, foram propostas as Regras Mínimas para o Tratamento de Prisioneiros e que teve seus trâmites aprovados para a efetiva aplicação no ano de 1984 .

Destarte, a previsão busca direcionar as condições essenciais pelas quais os presos devem ser submetidos. No entanto, reforça-se o seu caráter geral pelo fato de que cada nação possui um ordenamento jurídico diferente criando limitações para que as regras sejam admitidas integralmente, mas que objetiva o papel de promover a garantia de direitos.

No que se refere ao âmbito interno, os direitos dos presos são reforçados a partir da própria Constituição Federal de 1988 que dentre outras garantias, proíbe as penas cruéis em seu art. $5^{\circ}$, XLVII, e destaca o respeito à integridade física e moral da pessoa presa que se encontra no art. $5^{\circ}$, XLIX. Além disso, movimentos como os de organizações não

${ }^{28}$ PlANAlto. Lei $\mathrm{n}^{\circ}$ 7.210, de il de julho de 1984. Lei de Execução Penal. Disponível em http://www.planalto.gov.br/ccivil_03/leis/172Io.htm. Acesso em II mai. 2021. 
governamentais (ONGs) têm avançado na atuação por reconhecimento e valorização dos direitos humanos tanto no cenário nacional quanto internacional.

A partir desse contexto, o documento do Conselho de Direitos Humanos da ONU, o "Informe do relator especial sobre tortura e outros tratamentos ou penas cruéis, desumanos ou degradantes" 29 , da missão de 03 a 14 de agosto de 2015, conduzida por Juan Ernesto Méndez, no Brasil, apresenta um panorama geral sobre a realidade nas carceragens brasileiras.

Assim, o relator destaca a precariedade estrutural dos presídios como as fragilidades nas questões sanitárias e violências praticadas contra os presos. Em razão disso, busca fazer um alerta às autoridades internacionais a orientarem que o Brasil cumpra com as recomendações da instituição e com o que prevê a lei a fim de sanar as fragilidades identificadas e indicadas na missão oficial.

Durante a missão, o relator Juan Ernesto Méndez reuniu-se com representantes dos principais órgãos ligados às forças de Segurança Pública do país, em Brasília, capital federal. Além de visitar instalações penitenciárias e de se reunir com representantes e sociedade civil nos estados de São Paulo, Sergipe, Alagoas e Maranhão, segundo informações do item II. Atividades do Relator Especial, do informe da ONU.

De acordo com os dados disponíveis no relatório citado, a população carcerária brasileira correspondia à época a 71I,463 presos, incluindo aqueles em prisão domiciliar. Segundo o Sistema de Informações do Departamento Penitenciário Nacional SISDEPEN, o número de pessoas privadas de liberdade mantidas em unidades prisionais e outras prisões no país foi, em junho de 2020 , de 759,518 , o que equivale a 358.68 por Ioo.ooo habitantes.

Com base nos dados do "Monitor da Violência: raio X das prisões em 2021" 30 do Portal Gi em parceria com o Núcleo de Estudos da Violência (NEV) da USP e com o Fórum Brasileiro de Segurança Pública, publicado no dia 17 de maio de 2021, o total de presos no país é de 746,8 mil. Desse total, 217 mil são presos provisórios, ou seja, não

29 NAÇÕES UNIDAS. Informe del Relator Especial sobre la tortura y otros tratos o penas crueles, inhumanos o degradantes - Misión a Brasil. Disponível em https://acnudh.org/load/2016/o5/Gr6or416.pdf. Acesso em: 05 abr. 2021.

${ }^{30}$ PORTAL Gi. População carcerária diminui, mas Brasil ainda registra superlotação nos presídios em meio à pandemia. Disponível em https://gi.globo.com/monitor-da-violencia/noticia/2021/05/17/populacaocarceraria-diminui-mas-brasil-ainda-registra-superlotacao-nos-presidios-em-meio-a-pandemia.ghtml. Acesso em: I8 mai. 202I. 
chegaram a ter o direito a um julgamento. Apesar da redução, os números representam 54,9\% acima da capacidade e no Amazonas esse percentual atinge a marca de 196\%. Percebe-se, portanto, que o Brasil figura entre os países que mais aprisionam no mundo como pode-se notar nos dados apresentados na Figura i abaixo:

Figura I - Taxa de Aprisionamento por Ano - Brasil - 1990/2020.

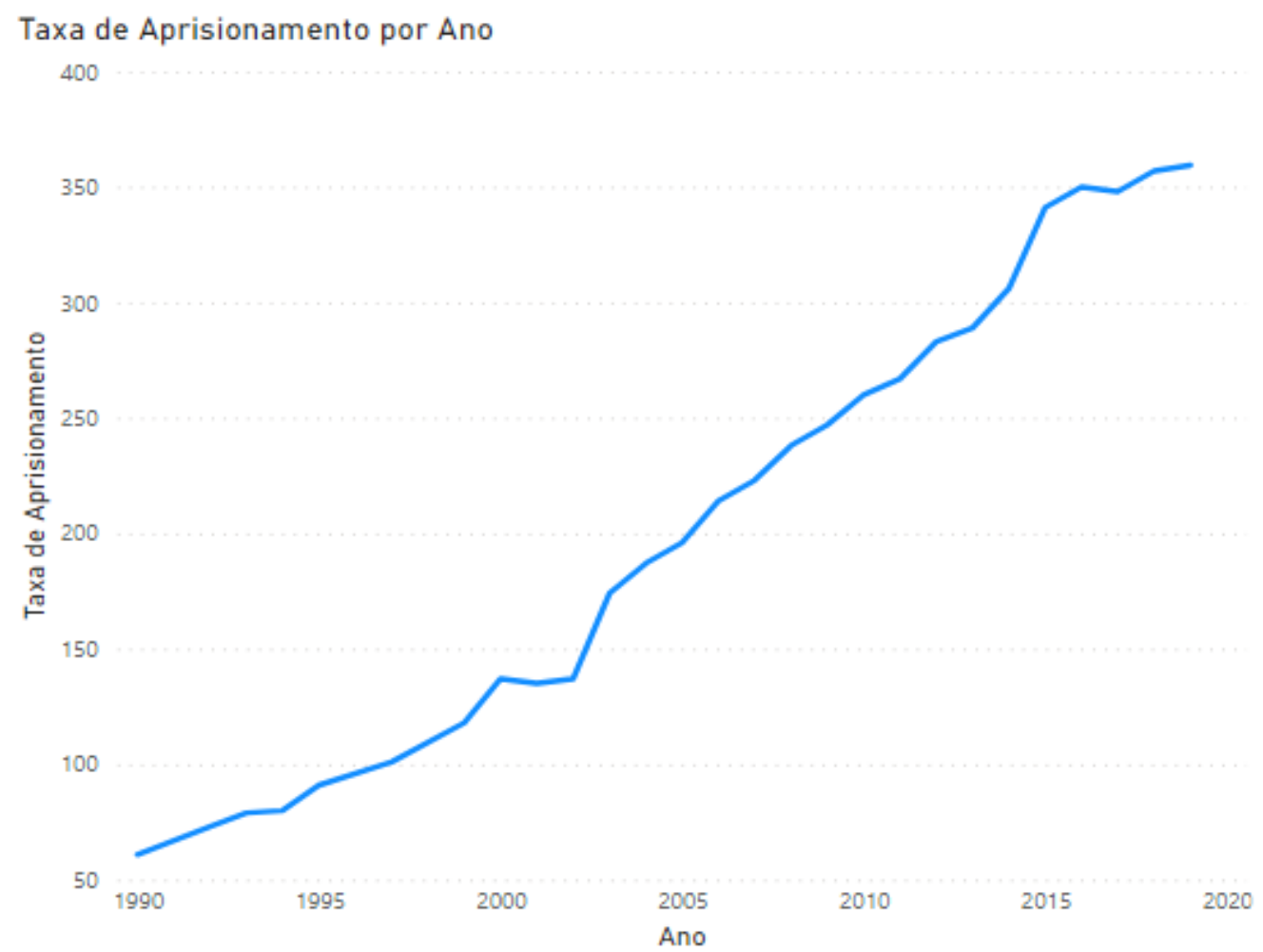

Fonte: Levantamento Nacional de Informações Penitenciárias (Infopen), 2019.

Nesse sentido, a capacidade dos presídios é insuficiente diante das taxas elevadas de encarceramento no país nas últimas décadas como nota-se na Figura 2 abaixo:

Figura 2 - Déficit Total e Vagas por Ano nas Penitenciárias Brasileiras - Valores Absolutos - Brasil $2000 / 2020$. 


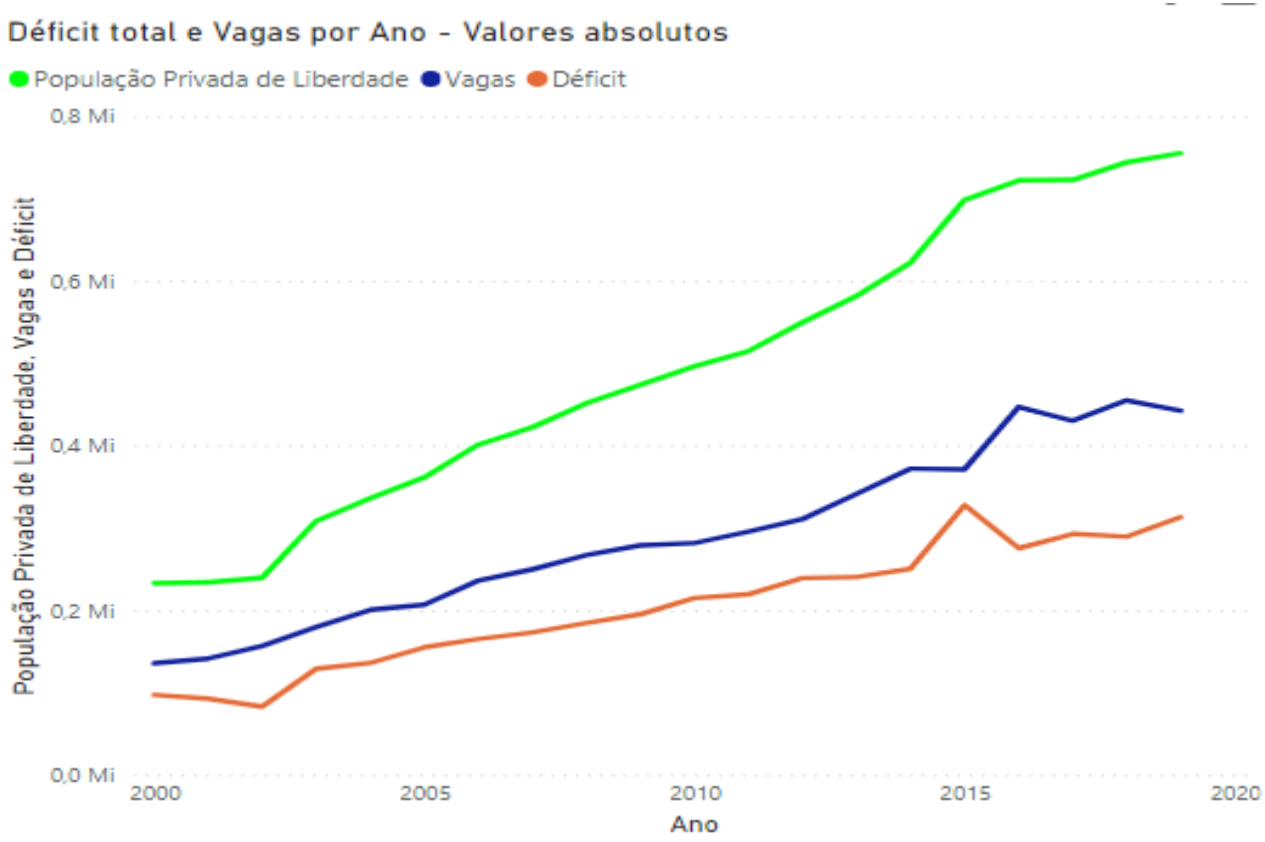

Fonte: Levantamento Nacional de Informações Penitenciárias (Infopen), 2019.

No que se refere à visita do relator ao Complexo de Pedrinhas, no Maranhão, a situação na unidade é nomeada de "explosiva" considerando a rivalidade entre facções. Além disso, denuncia-se a superpopulação ${ }^{3 \mathrm{I}}$, as condições sanitárias, de segurança e o constante risco de motins considerando-se que os presos permanecem entre 22 e 23 horas por dia em celas coletivas.

Nesse sentido, as denúncias de torturas tornaram-se frequentes, principalmente, no contexto de detenção, interrogatório policial e tratamento dos servidores da prisão. $O$ documento oficial menciona ainda objetos e meios utilizados para a prática da tortura como: chutes fortes, espancamentos (às vezes com paus e cassetetes), asfixia, choques elétricos com pistolas de choque, uso de spray de pimenta, gás lacrimogêneo, ruído de bombas e balas de borracha, intenso abuso verbal e ameaças são relatados como os métodos usados pela polícia e funcionários da prisão, configurando um contexto de uso excessivo de força e formas de punição.

Visto isso, o relator destaca a Lei $\mathrm{n}^{-}{ }_{13.06 \mathrm{o}^{32}}$, adotada em 22 de dezembro de 2014 , que dispõe sobre a prioridade do uso de armas não letais pelas forças de segurança,

\footnotetext{
${ }^{31}$ A superpopulação oficial nas prisões do Maranhão é de iII por cento (Infopen, 2014). No entanto, os dados são subestimados considerando que os números apresentados já se encontram em níveis de superlotações. ${ }^{32}$ PLANALTO. Lei $\mathrm{n}^{\circ}$ 13.06o, de 22 de dezembro de 2014. Disciplina o uso dos instrumentos de menor potencial ofensivo pelos agentes de segurança pública, em todo o território nacional.. Disponível em 
obedecendo aos princípios da legalidade, necessidade e proporcionalidade. Contudo, a referida lei não se aplica aos oficiais das prisões e não expressa quais armas estão e não estão permitidas, sendo necessário a revisão dos dispositivos do regulamento.

Percebe-se, portanto, que os casos de torturas são subnotificados e tratados de forma naturalizada. Segundo os últimos dados divulgados pelo Sistema de Informações do Departamento Penitenciário Nacional - SISDEPEN, referente ao primeiro semestre de 2020, foram registrados 1.309 óbitos no sistema prisional, dos quais 752 foram mortes naturais; 136, mortes intencionais; I04, suicídios; 5, mortes acidentais e 312 mortes com causas desconhecidas.

Em relação ao cenário da pandemia, à Agência Brasil com base em dados do Departamento de Monitoramento e Fiscalização do Sistema Carcerário e do Sistema de Execução de Medidas Socioeducativas (DMF/CNJ), registrou um aumento de $190 \%$ de óbitos por Covid-ı. Foram 58 mortes por Covid-ı́ entre servidores e pessoas em privação de liberdade nos primeiros 67 dias de 2021, somando 308 óbitos desde o início da pandemia em 2020. O total de casos da doença já são de 64.189 em presídios, sendo 48.143 entre presos e 16.046 entre servidores.

Isso evidencia a elevada taxa de mortalidade (naturais, homicídios, suicídios, mortes acidentais e outras) nas penitenciárias e, no caso da pandemia de Covid-ra, a medida de distanciamento social (mínimo de I metro) torna-se inviável. Vale ressaltar que as pessoas pertencentes a grupos raciais, sexuais, de gênero e outros grupos minoritários são as mais vulneráveis às violações. Logo, a falta de investigações ou mesmo a ausência do trabalho de médicos legistas contribuem para a impunidade.

\section{I Violações de direitos humanos no Complexo Penitenciário de Pedrinhas}

De acordo com a Conectas, organização não governamental voltada para a defesa de direitos humanos, o complexo enfrenta graves problemas estruturais e de superlotação. Estes por si só já equivalem a violações de direitos humanos que não necessita, necessariamente, haver a violação física. Como elemento agravante da situação, é que nas unidades estão presentes grupos de facções rivais que, por vezes, já entraram em conflito.

http://www.planalto.gov.br/ccivil_03/_ato2orI-

2014/2014/lei/lizo6o.htm\#: :text=LEI\%20N\%C2\%BA\%2013.06o\%2C\%2oDE\%2022,em\%2otodo\%200\%20territ

$\% \mathrm{C}_{3 \%} \mathrm{~B}_{3}$ rio\%2onacional. Acesso em o5 mai. 2021. 
Em matéria produzida pela Conectas ${ }^{33}$, em seu ápice de tensão, o presídio foi cenário de violentas rebeliões como a que ocorreu em 2013 e que resultou em 64 mortos, incluindo decapitações. À época, uma soma de esforços com medidas de contenção foi realizada entre o Governo do Maranhão e o Governo Federal como o envio de agentes para conter a rebelião. $\mathrm{Na}$ figura 3, exemplifica-se as marcas da violência no interior das unidades prisionais.

Figura 3 - Preso no Complexo Prisional de Pedrinhas exibe marcas de queimaduras nas costas. Segundo o detento, a ferida foi provocada por água quente jogada pelo policial que o prendeu. São Luís (MA) - Brasil.

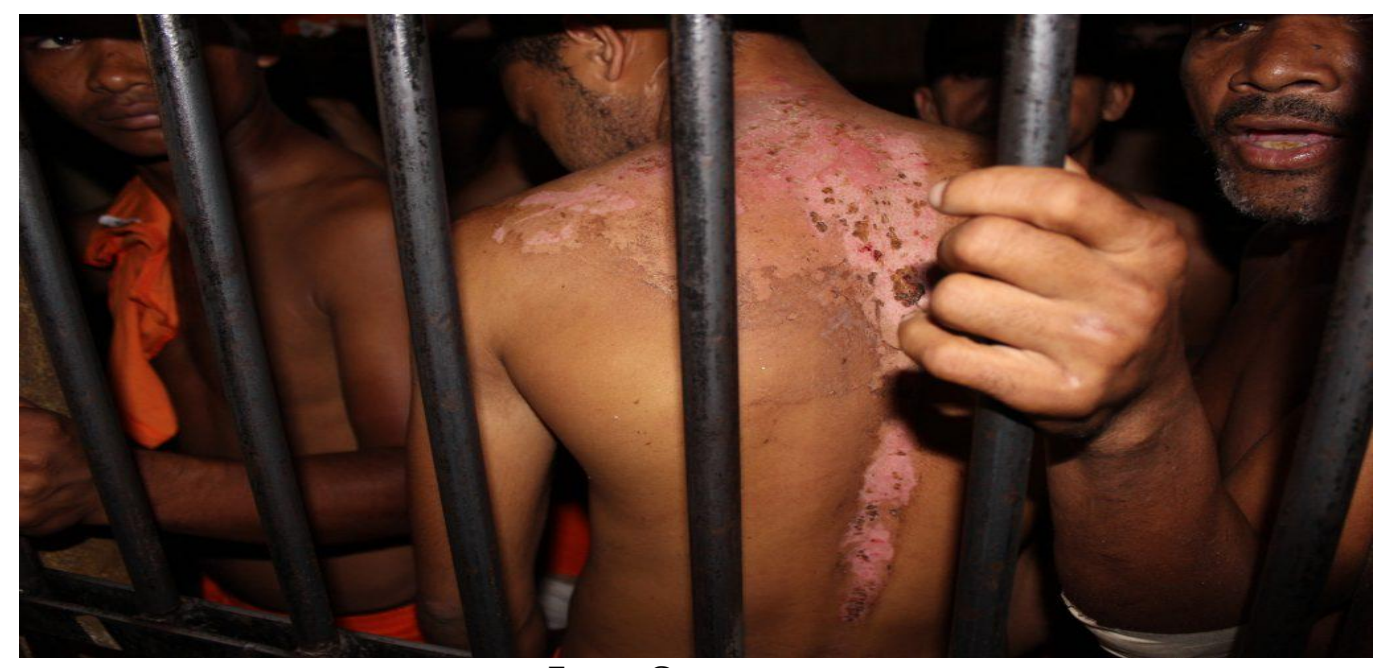

Fonte: Conectas.org.

Diante desse cenário, o presídio recebeu no ano de 2018 a visita de uma comitiva da Organização dos Estados Americanos (OEA). A organização destacou a necessidade de reforma do local seguindo a regulação internacional, as chamadas Regras de Mandela ${ }^{34}$, que tem normas específicas para higiene, condições climáticas, aquecimento e iluminação, além de determinar a separação dos presos por delitos cometidos, não apenas pela filiação a uma facção.

A comissão cobrou ainda do Tribunal de Justiça e do Ministério Público do Maranhão relatórios independentes de todos os presos mortos em Pedrinhas a partir de janeiro de 2015 em razão dos inquéritos terem sido arquivados. Segundo dados do Conselho

33 CONECTAS DIREITOS HUMANOS. Complexo de Pedrinhas: por dentro do presídio símbolo da falência do sistema prisional. Disponível em https://www.conectas.org/noticias/complexo-de-pedrinhaspor-dentro-do-presidio-simbolo-da-falencia-do-sistema-prisional. Acesso em: 07 abr. 202I.

${ }^{34}$ ESCRITÓRIO DAS NAÇÕES UNIDAS SOBRE DROGAS E CRIME. Regras Mínimas das Nações Unidas para o Tratamento de Reclusos (Regras de Nelson Mandela). Disponível em https://www.unodc.org/documents/justice-and-prison-reform/Nelson_Mandela_Rules-P-ebook.pdf. Acesso em: 07 abr. 202I. 
Nacional de Justiça (CNJ), a população carcerária do Maranhão em 2018 era de I0.42I presos e cerca de 1.079 presos sem condenação. Dentre as principais denúncias na visita, estão a baixa qualidade da comida e a lentidão no julgamento dos processos.

Nesse sentido, segundo o informe do Relator Especial da ONU em missão no Brasil, o presídio excede a capacidade de presos marcando a superlotação que gera um ambiente mais tenso e caótico nas palavras do Relator. Outra questão a considerar é o Complexo de Pedrinhas ter sob custódia presos de facções rivais, contribuindo para que o trato físico e psicológico seja mais violento. Um terceiro fator de grande destaque é a precarização das questões sanitárias em celas e banheiros tornando o ambiente ainda mais insalubre. Como também, a disponibilidade de itens básicos de higiene pessoal, levando a impactos negativos na higiene e saúde, incluindo doenças de pele e outras enfermidades.

Ainda tratando do informe da ONU, uma das principais queixas entre os presos é a má qualidade da alimentação que pode ter seu conteúdo comprometido desde o armazenamento até o momento de servir. Este fato colabora para o maior comprometimento das condições de saúde dentro das unidades que já contam com um mínimo de profissionais da área. O plano nacional de saúde para o sistema penitenciário e a política nacional de cuidados de saúde abrangentes para pessoas privadas de liberdade na prisão estabelecem o princípio de que o sistema público de saúde contemple todos os presidiários. Porém, esta não é a realidade que se vê na prática.

Diante do cenário de precarização identificado no Complexo Penitenciário de Pedrinhas; assim como, em outras unidades prisionais do país, algumas recomendações foram feitas. Dentre estas estão a de órgãos internacionais como o Conselho de Direitos Humanos da ONU, que sugere o efetivo cumprimento das leis vigentes, a proibição da tortura e de todas as outras formas cruéis de tratamento, a implementação de medidas com vistas a superar a superlotação, a revisão das formas de abordagens, entre outras. Além de propor uma cooperação com a assistência adequada da comunidade internacional nas áreas mencionadas.

\section{CONCLUSÃO}

Este trabalho identificou as violações de Direitos Humanos que fazem parte do cotidiano da população carcerária brasileira, com destaque para o caso específico do 
Complexo Penitenciário de Pedrinhas no período entre 2013 - 2015. Isso, motivado pelas denúncias levadas às instâncias máximas, como no caso do Conselho de Direitos Humanos da ONU.

Para isso, houve uma identificação nas legislações nacionais e internacionais que versam sobre os Direitos Humanos como a Constituição Federal de 1988 e a Declaração Universal dos Direitos Humanos da ONU. Além de apresentar a evolução histórica dos Direitos Humanos até a internalização das suas previsões no ordenamento interno brasileiro.

Nesse sentido, a superlotação carcerária vem demandando investimentos e implementação de políticas públicas eficazes em vista de reduzir o número de presos já condenados e, principalmente, aqueles que aguardam julgamento. Desta forma, o Estado e sua política de encarceramento vem acumulando um alto custo financeiro e social ao longo dos anos, além de revelar a necessidade de fortalecer os mecanismos de controle que regulam o cumprimento das leis.

Diante do exposto, conclui-se que as garantias legais às quais o Brasil se submete vêm sendo descumpridas no que se refere à garantia da dignidade humana das pessoas sob medidas restritivas de liberdade. Dessa forma, o Brasil descumpre o direito a um julgamento quando observa-se o elevado número de presos provisórios que aguardam julgamento, viola as normas de uso da força, a saúde e a higiene, principalmente, no cenário da pandemia da Covid-ı9. Logo, esse cenário contribui para a precarização de todo o processo até a recuperação do preso, além das más condições de trabalho dos servidores que integram o sistema prisional.

\section{BIBLIOGRAFIA}

AGÊNCIA BRASIL. Óbitos por covid-19 crescem 190\% no sistema prisional. Disponível em https://agenciabrasil.ebc.com.br/justica/noticia/202I-03/obitos-porcovid-19-crescem-19o-no-sistema-prisional. Acesso em: I7 mai. 2021.

BONAVIDES, Paulo. Curso de direito constitucional. ı8. ed. São Paulo: Malheiros, 2006.

BRASIL. Constituição (1988). Constituição da República Federativa do Brasil: promulgada em 5 de outubro de 1988. 4. ed. São Paulo: Saraiva, I990. 
BRASIL. Decreto no 40, de is de fevereiro de 199i. Convenção Contra a Tortura e Outros Tratamentos ou Penas Cruéis, Desumanos ou Degradantes. Diário Oficial da União: p. 3012, col. 2, Brasília, DF, i8 fev. 1991.

BRASIL. Decreto $\mathrm{n}^{\circ}$ 19.841, de 22 de outubro de 1945. Declaração Universal dos Direitos Humanos (DUDH). Disponível em http://www.planalto.gov.br/ccivil_o3/decreto/19301949/Di984I.htm. Acesso em: 18 mar. 2021.

CÂMARA DOS DEPUTADOS. Decreto ${ }^{\circ}$ 50215, de 28 de janeiro de 196r.Convenção relativa ao Estatuto dos Refugiados. Disponível em https://www2.camara.leg.br/legin/fed/decret/1960-1969/decreto-50215-28-janeiro-196I389887-publicacaooriginal-I-pe.html. Acesso em o5 mai. 202I.

CIDH - COMISSÃO INTERAMERICANA DE DIREITOS HUMANOS. Convenção Americana sobre Direitos Humanos. Disponível em https://www.cidh.oas.org/basicos/portugues/c.convencao_americana.htm. Acesso em: 05 mai. 202I.

CONECTAS DIREITOS HUMANOS. Complexo de Pedrinhas: por dentro do presídio símbolo da falência do sistema prisional. Disponível em https://www.conectas.org/noticias/complexo-de-pedrinhas-por-dentro-do-presidiosimbolo-da-falencia-do-sistema-prisional. Acesso em: 07 abr. 2021.

CUT - CENTRAL ÚNICA DOS TRABALHADORES. Convenção Interamericana Contra o Racismo, Discriminação Racial e Formas Relacionadas de Intolerância. Disponível em https://www.cut.org.br/system/uploads/ck/files/interamericantreatiesA68ConvencaoInteramericanaracismoPOR.pdf. Acesso em: 05 mai. 2021.

DEPEN - DEPARTAMENTO PENITENCIÁRIO NACIONAL. Depen lança dados do Sisdepen do primeiro semestre de 2020. Disponível em https://www.gov.br/depen/pt$\mathrm{br} /$ assuntos/noticias/depen-lanca-dados-do-sisdepen-do-primeiro-semestre-de-

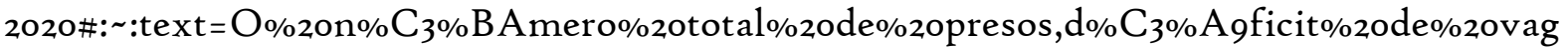
as\%2otamb\% $\mathrm{C}_{3 \% \mathrm{~A}}$ 9m\%2ocaiu. Acesso em: 30 mar. 202I.

DEPEN -DEPARTAMENTO PENITENCIÁRIO NACIONAL. Levantamento Nacional de Informações Penitenciárias. Disponível em https://app.powerbi.com/view?r=eyJrIjoiMmU4 ODAwNTAtY2IyMSooOWJiLWE3ZT gtZGNjY2ZhNTYzZDliliwidCI6ImViMDkwNDIwLTQoNGMtNDNmNyosMWYy LTRiOGRhNmJmZThlMSJ9. Acesso em: 05 abr. 202I. 
DEPEN - DEPARTAMENTO PENITENCIÁRIO NACIONAL. Relatórios Analíticos Infopen. Disponível em https://www.gov.br/depen/pt-br/sisdepen/maisinformacoes/relatorios-infopen/brasil. Acesso em: II mai. 2021.

DIREITOS HUMANOS NA INTERNET. Conselho de Direitos Humanos - CDH. Disponível em http://www.dhnet.org.br/abc/onu/conselhos_dh.htm. Acesso em: 04 mai. 2021.

ESCRITÓRIO DAS NAÇÕES UNIDAS SOBRE DROGAS E CRIME. Regras Mínimas das Nações Unidas para o Tratamento de Reclusos (Regras de Nelson Mandela). Disponível em https://www.unodc.org/documents/justice-and-prisonreform/Nelson_Mandela_Rules-P-ebook.pdf. Acesso em: 07 abr. 202I.

GLOBOPLAY. OEA visita Complexo Penitenciário de Pedrinhas. Disponível em https://globoplay.globo.com/v/7143645/. Acesso em: 07 abr. 2021.

JUS BRASIL. Supremo Tribunal Federal. Íntegra da Declaração Universal dos Direitos Humanos. Disponível em https://stf.jusbrasil.com.br/noticias/362108/integra-dadeclaracao-universal-dos-direitos-humanos. Acesso em: 04 mai. 202I.

NAÇÕES UNIDAS. Informe del Relator Especial sobre la tortura y otros tratos o penas crueles, inhumanos o degradantes - Misión a Brasil. Disponível em https://acnudh.org/load/2016/05/Gi6or4I6.pdf. Acesso em: 05 abr. 2021.

OAS - ORGANIZATION OF AMERICAN STATES. Convenção Internacional sobre a Proteção dos Direitos de todos os Trabalhadores Migrantes e Membros de suas Famílias. Disponível em https://www.oas.org/dil/port/1990\%20Conven\%C3\%A 7\%C3\%A30\%20Internacional\%20s

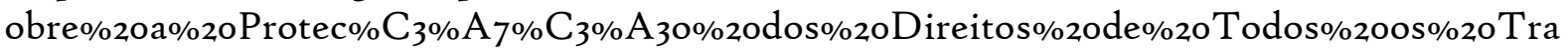
balhadores\%2oMigrantes\%2oe\%20suas\%2oFam\%C3\%ADlias,\%20a\%2oresolu\% $\mathrm{C}_{3} \% \mathrm{~A}_{7} \% \mathrm{C}_{3}$ \%A30\%2045-158\%20de\%2018\%20de\%2odezembro\%20de\%201990.pdf. Acesso em: o5 mai. 2021.

OAS - ORGANIZATION OF AMERICAN STATES. Pacto Internacional sobre Direitos Civis e Políticos (1966). Disponível em https://www.oas.org/dil/port/1966\%20Pacto\%2oInternacional\%20sobre\%2oDireitos\%20C ivis\%20e\%2oPol\%C3\%ADticos.pdf. Acesso em: 05 mai. 2021.

ONU BRASIL. Há 70 anos: adotada a Declaração Universal dos Direitos Humanos. Disponível em https://www.youtube.com/watch?v=SJyıM4iYiMo. Acesso em: 04 mai. 2021. 
ONU - ORGANIZAÇÃO DAS NAÇÕES UNIDAS. Declaração Universal dos Direitos Humanos da ONU. Disponível em https://brasil.un.org/pt-br/9i6or-declaracaouniversal-dos-direitos-humanos. Acesso em: 18 mar. 2021.

PLANALTO. Decreto $n^{\circ} 4246$, de 22 de maio de 2002. Convenção relativa ao Status de Pessoas Apátridas. Disponível em http://www.planalto.gov.br/ccivil_03/decreto/2002/D4246.htm. Acesso em 05 mai. 202I.

PLANALTO. Decreto $\mathrm{n}^{\circ}$ 8766, de II de maio de 2016. Convenção Interamericana sobre Desaparecimento Forçado de Pessoas. Disponível em http://www.planalto.gov.br/ccivil_03/_ato2015-2018/2016/decreto/D8766.htm. Acesso em 05 mai. 2021.

PLANALTO. Decreto ${ }^{\circ}$ 6949, de 25 de agosto de 2009. Convenção sobre os Direitos das Pessoas com Deficiência. Disponível em http://www.planalto.gov.br/ccivil_03/_ato20072010/2009/decreto/d6949.htm. Acesso em 05 mai. 2021.

PLANALTO. Decreto $n^{\circ} 4377$, de 13 de setembro de 2002. Convenção sobre a Eliminação de Todas as Formas de Discriminação contra Mulheres. Disponível em http://www.planalto.gov.br/ccivil_03/decreto/2002/d4377.htm. Acesso em 05 mai. 2021.

PLANALTO. Decreto $\mathrm{n}^{\circ} \mathrm{1973}$, de $\mathrm{I}^{\circ}$ de agosto de 1996 . Convenção Interamericana para a Prevenção, Punição e Erradicação da Violência contra a Mulher. Disponível em http://www.planalto.gov.br/ccivil_03/decreto/r996/di973.htm. Acesso em 05 mai. 202I.

PLANALTO. Decreto $n^{\circ}$ 98386, de o9 de dezembro de 1989. Convenção Interamericana para Prevenir e Punir a Tortura Disponível em http://www.planalto.gov.br/ccivil_03/Decreto/r980-1989/D98386.htm. Acesso em o5 mai. 2021.

PLANALTO. Decreto $\mathrm{n}^{\circ} 8767$, de II de maio de 20I6. Convenção Internacional para a Proteção de Todas as Pessoas contra o Desaparecimento Forçado. Disponível em http://www.planalto.gov.br/ccivil_03/_ato2015-2018/2016/decreto/D8767.htm. Acesso em 05 mai. 202I.

PLANALTO. Decreto $\mathrm{n}^{\circ}$ 65810, de o8 de dezembro de 1969. Convenção Internacional sobre a Eliminação de todas as Formas de Raça Discriminação. Disponível em http://www.planalto.gov.br/ccivil_03/decreto/1950-1969/D6581o.html. Acesso em o5 mai. 202I. 
PLANALTO. Decreto ${ }^{\circ}$ 997Io, de II de novembro de 1990. Convenção sobre os Direitos da Criança. Disponível em http://www.planalto.gov.br/ccivil_03/decreto/r99o1994/d99710.htm. Acesso em o5 mai. 2021.

PLANALTO. Lei $\mathrm{n}^{\circ}$ 13.06o, de 22 de dezembro de 2014. Disciplina o uso dos instrumentos de menor potencial ofensivo pelos agentes de segurança pública, em todo o território nacional.. Disponível em http://www.planalto.gov.br/ccivil_03/_ato20II2014/2014/lei/lizo6o.htm\#: : :text=LEI\%20N\%C2\%BA\%2013.060\%2C\%20DE\%2022,em\%20t odo\%200\%2oterrit\% $\mathrm{C}_{3 \%} \% \mathrm{~B}_{3}$ rio\%2onacional. Acesso em 05 mai. 2021.

PLANALTO. Decreto $n^{\circ} 4388$, de 25 de setembro de 2002. Estatuto de Roma do Crime Internacional $\quad$ Quadra. $\quad$ Disponível em http://www.planalto.gov.br/ccivil_03/decreto/2002/d4388.htm. Acesso em 05 mai. 202I.

PLANALTO. Lei $n^{\circ}$ 7.210, de in de julho de 1984. Lei de Execução Penal. Disponível em http://www.planalto.gov.br/ccivil_03/leis/172Io.htm. Acesso em II mai. 202I.

PORTAL Gi. População carcerária diminui, mas Brasil ainda registra superlotação nos presídios em meio à pandemia. Disponível em https://gi.globo.com/monitor-daviolencia/noticia/2021/05/17/populacao-carceraria-diminui-mas-brasil-ainda-registrasuperlotacao-nos-presidios-em-meio-a-pandemia.ghtml. Acesso em: I8 mai. 202I.

UNIDOS PARA OS DIREITOS HUMANOS. Uma breve História dos Direitos Humanos. Disponível em https://www.unidosparaosdireitoshumanos.com.pt/what-arehuman-rights/brief-history/. Acesso em: 04 mai. 202I.

RAMOS, André de Carvalho. Curso de direitos humanos. - 4. ed. - São Paulo: Saraiva, 2017.

SALA, José Blanes. Relações internacionais e Direitos humanos. Revista Cultura Acadêmica; Marília: Oficina Universitária. Io6p. São Paulo, 201 .

UNIDOS PELOS DIREITOS HUMANOS. As origens dos Direitos Humanos. Disponível em https://www.unidosparaosdireitoshumanos.com.pt/course/lesson/background-ofhuman-rights/the-background-of-human-rights.html. Acesso em: 04 mai. 2021. 